\title{
Saúde do trabalhador: considerações a partir da crítica da economia política
}

\author{
Ricardo Lara
}

Universidade Federal de Santa Catarina (UFSC)

\section{Saúde do trabalhador: considerações a partir da crítica da economia política}

Resumo: O presente artigo tem por objetivo abordar a saúde do trabalhador, buscando fundamentação na crítica da economia política. Procura compreender as causas dos adoecimentos e acidentes dos trabalhadores, como também destacar elementos para pensar as lutas da classe trabalhadora, no âmbito da saúde, principalmente no que se refere às políticas públicas e à prática sindical. Infere que os trabalhadores, nas contemporâneas relações de trabalho, adoecem e acidentam-se devido aos ritmos intensificados da produção, seja nas atividades desenvolvidas no chão da fábrica ou na gerência científica do trabalho.

Palavras-chave: Saúde do trabalhador. Política pública. Crítica da economia política.

\section{Worker's Health: Considerations Based on a Criticism of Political Economy}

Abstract: The purpose of this article is to analyze worker health, based on a criticism of political economy. It seeks to understand the causes of illnesses and accidents among workers, and to highlight elements to consider the struggles of the working class in the realm of health, principally concerning public policies and union practices. It infers that under contemporary labor relations, workers get ill and have accidents due to the intensified pace of production, whether in activities on the factory floor or in scientific management of labor. Key words: Labor health. Public policy. Critique of political economy. 


\section{Introdução}

A máquina, que produz em grande escala, tem provocado a escassez. Nossos conhecimentos fizeram-nos céticos. Nossa inteligência, empedernidos e cruéis.

Pensamos em demasia e sentimos bem pouco.

Mais do que máquinas, precisamos de humanidade. Charles Chaplin

A saúde do trabalhador ganha relevância e urgência no âmbito das políticas sociais, os sindicatos, empresários, gestores e trabalhadores enfatizam em suas agendas o importante debate sobre as condições de adoecimentos e de doenças do trabalho.

O trabalho, no modo de produção capitalista, é determinado pelo processo de produção, no qual acidentar e adoecer são resultantes de relações sociais em que o trabalhador torna-se apêndice da máquina. $\mathrm{O}$ trabalho que deveria gerar prazer, felicidade, na ordem do capital, causa fadiga, doenças, acidentes, sofrimentos físicos e mentais. Muitos acidentes de trabalho, quando não matam, podem deixar mutilações e dependências.

A inquietação e a defesa da saúde do trabalhador devem ser encaradas como luta da classe trabalhadora, que busca avançar nas conquistas de melhorias nas políticas públicas, voltadas para atender a saúde do trabalhador, como condição emergencial. Nos mais diversos espaços produtivos, notamos que a saúde do trabalhador padece de todos os castigos impostos à força de trabalho - reduzida não só à condição de mercadoria, mas de principal mercadoria do modo de produção capitalista -, pois é da extração do sobretrabalho intensivo, da mais-valia, que as condições são propícias para acumulação de capital.

A produção capitalista, nos últimos 40 anos, intensificou mudanças no espaço produtivo. O processo de reestruturação produtiva trouxe inovações como a robótica e a automação microeletrônica aplicadas à produção; as novas modalidades de gestão de produção, tais como os Círculos de Controle de Qualidade e Programas de Qualidade Total; a série de racionalização da produção, tais como os downsizing e a reengenharia (muitas das raciona- lizações produtivas decorreram de novos patamares de centralização e concentração do capital, por meio de fusões, aquisições e diversificações corporativas, que implicaram - e ainda implicam - em demissões em massa). Além disso, são importantes componentes do complexo de reestruturação produtiva, dos vários tipos de descentralização, tais como a terceirização ou as relocalizações industriais, que implicam o fechamento de fábricas num local e abertura em outro, ou, ainda, a instauração de legislações trabalhistas de cariz flexível, que criam nova regulação institucional do trabalho assalariado, adaptando-o às necessidades imperiosas do capital em fase de mundialização (ALVES, 2000). Esse conjunto de inovações tecnológicas e organizacionais ocasionou as diversas desregulamentações das relações de trabalho e atingiu, por consequência, a saúde do trabalhador.

As inovações tecnológicas trouxeram consigo a intensificação do trabalho. A Lesão por Esforço Repetitivo (LER), na atualidade, é uma das principais doenças do trabalho, nos vários ramos produtivos, passando dos tradicionais, como vestuário e calçados, aos modernos, como informática. A utilização de máquinas e a robotização, em alguns casos, aliviaram a carga física do trabalho, mas o processo de automação passou a exigir maior destreza das mãos. Agora, o esforço físico demandado é de outra natureza. É um esforço leve e, por isso, capaz de ser repetido em alta velocidade pelas mãos e pelos dedos por várias vezes, e cobra, ao mesmo tempo, uma postura estática e a sobrecarga dos segmentos do corpo (SANTOS, 2005).

As mudanças na esfera produtiva intensificaram a exploração da força de trabalho e o desgaste da saúde do trabalhador. Poucos esforços foram feitos no sentido de minimizar as condições de sofrimento no trabalho; em contrapartida, muito se pensou no avanço da produtividade do capital. No âmbito das políticas sociais, o Estado, pautado no ideário neoliberal, abandonou os mecanismos de seguridade social: muitos trabalhadores adoecidos e acidentados encontram dificuldades para serem atendidos pela política pública, ou mesmo para ter o simples reconhecimento de suas condições de adoecimento como doença ocupacional. Em muitos casos, a situação de acidentado ou adoecido pode levar ao desemprego. 
A competitividade entre os próprios trabalhadores por um posto de trabalho gera angústia e ansiedade, o que faz aumentar as tensões psicológicas e pode acarretar distúrbios mentais e lesões. No setor de serviços, por exemplo, ganham destaque as doenças do trabalho que exigem alta capacidade cognitiva. O trabalho resume-se em números, cálculos, sinais luminosos, mostradores, teclados e monitores em que o erro do trabalhador implica repercussões com responsabilidades excessivas. Somam-se a esses fatores o trabalho sentado, repetitivo, monótono e uma vida sedentária fora do trabalho (SANTOS, 2005).

As novas tendências do mundo do trabalho comprovam a velha afirmação de que o instrumental de trabalho utiliza-se do trabalhador e não o trabalhador do instrumental. Na atualidade, as mudanças no espaço produtivo ao mesmo tempo em que realizam inovações tecnológicas e organizacionais agravam a saúde do trabalhador. Há um conjunto de inseguranças nas relações de trabalho que provocam mal-estar físico e mental à classe trabalhadora.

É por causa deste contexto do mundo do trabalho que as organizações de luta da classe trabalhadora devem ficar atentas e vigilantes com a saúde e os processos causadores de doenças nos mais diversos ambientes de trabalho.

\section{Os fundamentos da crítica do sofrimento do trabalhador}

O trabalho como criador de "valor-de-uso é indispensável à existência da sociedade humana" (MARX, 2002, p. 60). O homem em "quaisquer que sejam as formas de sociedade" recorrerá ao trabalho, atividade mediadora entre ele e natureza, para suprir sua sobrevivência. $\mathrm{O}$ ser humano transforma a natureza pelo trabalho. Ao modificar a natureza, coloca em movimento as capacidades do seu próprio corpo que, ao atuar no processo de trabalho no modo de produção capitalista, encontram "instrumentos de trabalho" altamente desenvolvidos.

Facilitar ou diminuir o esforço do trabalhador no processo de trabalho deveria ser o principal objetivo do desenvolvimento dos "instrumentos de trabalho", mas, no modo de produção capitalista, inverte-se a lógica, o trabalhador torna-se apêndice da máquina, pois é ele que deve se ajustar ao aparato produtivo. Segundo Marx (2002, p. 748):

Graças ao progresso da produtividade do trabalho social, quantidade sempre crescente de meios de produção pode ser mobilizada com um dispêndio progressivamente menor de força humana. Este enunciado é uma lei na sociedade capitalista, onde o instrumental de trabalho emprega o trabalhador, e não este o instrumental [...].
Diante dessa observação, notamos que o modo de produção capitalista tem uma lógica própria. Com os progressos dos meios de produção - no caso os "instrumentos de trabalho", que se convertem em "trabalho morto" -, há uma possível "vitória" da máquina sobre a força de trabalho. "Triunfo" que, se fosse adequado pela "lógica do trabalho", facilitaria a vida do trabalhador, pois ele teria mais "tempo livre", já que a máquina realiza o trabalho de vários homens. Pela "lógica do trabalho", o "instrumental de trabalho" (máquina) pode oferecer ao trabalhador uma vida repleta de liberdade, bem distante do "trabalho alienado" que degenera, adoece e acidenta.

Na lógica do capital, o "instrumental" utiliza-se do trabalhador, tornando-o supérfluo e/ou apêndice da produção. O trabalhador deve adequar-se à produção, o maquinário determina as condições e ritmos do processo produtivo. O aperfeiçoamento das máquinas e instrumentos de trabalho não objetiva reduzir o esforço do trabalhador, a principal finalidade é aprimorar o processo de trabalho para produzir mais em menos tempo e, por conseguinte, ter o menor gasto possível com a força de trabalho.

Seria equivocado pensar que, com o desenvolvimento da máquina, a força de trabalho seria, necessariamente, eliminada da produção. Há diminuição do número de trabalhadores diretamente empregados na produção, mas o desemprego não é simplesmente resultado do desenvolvimento das forças produtivas. A substituição de trabalhadores por máquinas é resultado das relações sociais de produção, de uma condição de produção "especificamente capitalista", da "subsunção real" do trabalho ao capital.

Para Marx (1985, p. 105),

\begin{abstract}
Na subsunção real ao capital [...] desenvolvem-se as forças produtivas sociais do trabalho e, graças ao trabalho em grande escala, chega-se à aplicação da ciência e da maquinaria à produção imediata. Por um lado, o modo de produção capitalista, que agora se estrutura como um modo de produção sui generis, origina uma forma modificada de produção material. Por outro lado, essa modificação da forma material constitui a base para o desenvolvimento da relação capitalista, cuja forma adequada corresponde, por consequência, a determinado grau de desenvolvimento alcançado pelas forças produtivas do trabalho.
\end{abstract}

Apenas quando as formas de trabalho enfrentam o trabalhador como coisa e dele não mais dependem é que o capital subsume realmente o trabalho. $\mathrm{O}$ "modo de produção especificamente capitalista" é aquele no qual o trabalho é subsumido realmente, através de um desenvolvimento do próprio trabalho social em conjunto com a aplicação da ciência, tornando os trabalhadores supérfluos, estranhos à relação de 
produção, que agora independe deles quanto mais se autonomiza através do desenvolvimento da maquinaria. Isso ocorre quando a "aplicação tecnológica da ciência transforma forças naturais em maquinaria, a qual substitui o trabalhador e o subjuga, tornando-o supérfluo" (TRISTÃO, 2008, p. 8-9).

A produção capitalista é produção e reprodução social. As relações sociais estabelecem-se sobre o antagonismo de classes e de sua principal estrutura, a "propriedade privada dos meios fundamentais de produção", que sempre são aprimorados com a aplicação da ciência. O trabalho assalariado e o capital pressupõem existências sociais conflitantes que se condicionam e reproduzem em todos os aspectos da vida social. Disso resulta que:

Quanto maiores a riqueza social, o capital em função, a dimensão e energia de seu crescimento e, consequentemente, a magnitude absoluta do proletariado e da força produtiva do seu trabalho, tanto maior o exército industrial de reserva [...]. Esta é a lei geral, absoluta, da acumulação capitalista [...] (MARX, 2002, p. 748).

Quanto maior for o "capital constante", que mais facilmente proporciona a produção da riqueza material, menor se torna o "capital variável", ou seja, quanto mais desenvolvidos estiverem os "meios de produção", menos espaço terá à força de trabalho empregada na produção. Esse processo é desencadeado com a "autonomização do instrumental de trabalho", que se confronta com o trabalhador como capital - é o "trabalho morto" que passa a dominar a força de trabalho viva. A separação entre as forças intelectuais do processo de produção e o trabalho manual e, por conseguinte, a transformação delas em poderes de domínio do capital sobre o trabalho, torna-se uma realidade consumada na grande indústria protoformada na maquinaria.

A crítica da economia política desvendou que o trabalho, no modo de produção capitalista, interessa como trabalho produtivo, criador de valores de troca. O trabalhador é possuidor da força de trabalho e o capitalista é dono dos meios de produção, mas a mercadoria especial é a força de trabalho que, ao ser explorada, gera a mais-valia ${ }^{1}$. É possível acumular capital somente a partir do momento em que há condições para explorar força de trabalho. A produção capitalista não é simplesmente produção de mercadorias, é essencialmente produção de mais-valia. $\mathrm{O}$ trabalhador produz não para si, mas para o capital. Apenas é produtivo o trabalhador que produz maisvalia para o capitalista ou serve à autovalorização do capital (MARX, 1984, p. 105).

O trabalho produtivo, que objetiva unicamente o excedente, encontra-se enraizado na sociedade capitalista e, a partir da concretização de tal vivência, o trabalho está muito longe de representar aquele momento de realização humana, de produção de respostas às suas carências autênticas. $\mathrm{O}$ trabalho transforma-se numa atividade prática negativa, alienada, isto é, numa forma particular de atividade que degenera o homem. Na sociedade do trabalho produtivo, o capital é o maior regente, reduzindo-o a mero produtor de valor-de-troca, o "trabalho abstrato". Nessa particular relação social, surgem inúmeras formas de desumanização, destacandose: a divisão social do trabalho, o domínio dos instrumentos de trabalho sobre a força de trabalho ${ }^{2}$, o que ocasiona o adoecimento, o sofrimento no trabalho.

No processo de produção e reprodução da vida social, orientado pelo trabalho criador de valores-detroca, que é impulsionado pela produção industrial, os indivíduos realizam suas atividades práticas nas organizações industriais, ambientes de total "estranhamento" entre trabalhador e produto de seu trabalho. Com o advento do trabalho abstrato, assegurado com a "grande indústria e a maquinaria", o trabalho não é concebido como atividade prática criativa, na qual o homem exterioriza a sua capacidade inventiva, o homem não se reconhece como criador do objeto. $\mathrm{O}$ intercâmbio com a natureza é realizado nas organizações industriais sob a forma de "trabalho assalariado do capital", produtor de mercadoria e gerador de riqueza para os proprietários dos meios de produção, seguido de miséria para a força de trabalho. O trabalho na sociedade capitalista é causa de toda degeneração intelectual, de toda deformação orgânica. Os homens são embrutecidos pelo processo de produção. O trabalho alienado é, pois, necessariamente fonte de acidentes e adoecimentos.

Adoecer e acidentar no trabalho são fatores presentes na vida do trabalhador, pois o mote da acumulação capitalista é o uso da força de trabalho pela máquina. Distante está o alívio do trabalhador das atividades árduas. O tempo livre que o desenvolvimento da maquinaria e a aplicação da ciência na produção poderia e pode oferecer ao trabalhador está longe dos objetivos da acumulação capitalista, pelo menos até quando pairar os domínios da burguesia sobre as forças produtivas.

\section{A política de saúde do trabalhador}

O modo de produção capitalista possibilitou as condições técnicas para uma vida emancipada do trabalho alienado, que penaliza, degrada e adoece o homem. Entretanto, as relações sociais da ordem do capital, que se nutrem na propriedade privada dos meios de produção, colocam obstáculos para os trabalhadores terem acesso a uma vida cheia de sentido dentro e fora do trabalho.

Analisar a saúde do trabalhador, na sociedade capitalista, é uma tarefa, no mínimo, muito difícil para 
manter a coerência das análises, pois, conforme lembramos na seção anterior, o instrumento de trabalho utiliza-se do trabalhador e não o trabalhador usufrui do instrumento de trabalho. No entanto, a inquietação sobre as relações de trabalho deve ser perene, pois não podemos considerá-las como relações naturais e eternas da sociedade humana ${ }^{3}$. A sociabilidade capitalista oculta as relações sociais de produção e as

[...] fórmulas que pertencem, claramente, a uma formação em que o processo de produção domina o homem, e não o homem o processo de produção, [assim,] são consideradas pela consciência burguesa uma necessidade tão natural quanto o próprio trabalho produtivo (MARX, 2002, p. 102).

A vida material e espiritual dos homens, no capitalismo, é condicionada à vivência reificada, nutrida de complexos sociais fetichizantes que impõem valores, costumes e formas de ser e existir que carregam a negação da emancipação do trabalho. $\mathrm{O}$ trabalho alienado é a negação da condição humana como vivência emancipada.

Tomando esses pressupostos de análise, compreendemos, portanto, que a discussão sobre saúde do trabalhador torna-se pertinente quando a realizamos de forma crítica e com o objetivo de desenvolver argumentos para a classe trabalhadora projetar "mudanças sociais", que neguem radicalmente as condições vigentes de vida dentro e fora do trabalho.

Nos últimos 40 anos, vivenciamos momentos críticos para aqueles que sobrevivem da venda da sua força de trabalho. Emergiram, simultaneamente, as crises da "materialidade" e da "espiritualidade" da classe trabalhadora. A primeira atingiu a "objetividade" da classe trabalhadora, acarretando metamorfoses agudas no processo de trabalho, e a segunda alcançou o plano da "subjetividade do trabalho". Para Antunes (2000, 2001) a primeira crise que atingiu a "materialidade do trabalho" ocorreu principalmente com o avanço tecnológico. A revolução técnica da segunda metade do século 20, como a automação, a robótica, a microeletrônica e as novas formas de organização da produção, como a terceirização, o que provocou mudanças substantivas na esfera produtiva. A segunda crise, como resultante da primeira, atingiu a "subjetividade da classe trabalhadora", sua consciência de classe, a "consciência de constituir-se como ser que vive do trabalho". As mudanças na base material repercutem na espiritualidade da classe trabalhadora que, no final do século 20 e no início do 21 , apresenta-se "complexificada, heterogeneizada e fragmentada". Nesse contexto adverso, cobra-se, portanto, maior esforço das lutas sociais do trabalho diante da exploração do capital. A precarização do trabalho e os abalos nas estruturas clássicas de organização política dos trabalhadores desafiam a possibilidade da revolução do trabalho. Instala-se a crise do trabalho abstrato. Sinteticamente, podemos dizer que há uma crise do "trabalho abstrato", produtor de valor-de-troca e jamais uma superação ou crise do "trabalho concreto", produtor de valor-de-uso, meio necessário e indispensável para sobrevivência do homem.

Perante o movimento do capital e sua forma específica de explorar a força de trabalho para obter a valorização e acumulação, cabe a nós desenvolvermos algumas considerações sobre a relação trabalho e saúde na contemporaneidade. Hoje, apesar dos avanços significativos no campo conceitual que apontam um novo enfoque e novas práticas para lidar com a relação trabalho e saúde, consubstanciados sob a denominação de "saúde do trabalhador", depara-se, no cotidiano das lutas sociais do trabalho, com as hegemonias da Medicina do Trabalho e da Saúde Ocupacional. Tal fato coloca em questão a já identificada distância entre os interesses antagônicos da sociedade capitalista, sobretudo num campo potencialmente ameaçador, em que a busca de soluções quase sempre se confronta com interesses econômicos arraigados e imediatistas, que não contemplam os investimentos indispensáveis à garantia de uma política em defesa do trabalho (MINAYO-GOMEZ; THEDIM-COSTA, 1997, p. 23).

O debate sobre saúde do trabalhador, a partir de 1980, década em que o país passa por um processo de redemocratização, vem se desenvolvendo com práticas no âmbito da Saúde Pública, com atuações importantes dos sindicatos e avanços significativos no âmbito acadêmico, o que possibilitou a denominação de saúde do trabalhador, quando o assunto em questão é trabalho e saúde daqueles que produzem a riqueza material.

Lacaz (2002, p. 1) relembra que:

[...] o 'movimento' da Saúde do Trabalhador como campo de práticas e conhecimentos surge com a consolidação do operariado industrial urbano nos países da América Latina e, no caso do Brasil, avança na conjuntura de redemocratização do país, em que o movimento social dos trabalhadores retorna à cena política, estabelecendo uma outra relação entre Estado e Sociedade [...]. Não é errôneo afirmar que a luta da sociedade civil brasileira pela redemocratização é consagrada na Constituição Federal de 1988 e seus reflexos para a saúde pública consubstanciam-se na proposta do Sistema Único de Saúde (SUS), conforme prescreve o Título VII, Capítulo II, Secção II, artigos 196 a 200. Frise-se que ao SUS cabe a atuação em Saúde do Trabalhador, através de ações e serviços de saúde públicos que busquem a promoção e proteção da saúde dos que trabalham e de medidas que coloquem sob seu controle os Serviços de Medicina do Trabalho das empresas. 
A partir dessa constatação, cabe aproximar o debate sobre as alterações nas condições e relações de trabalho que intensificaram as doenças do trabalho, na contemporaneidade. De uma forma geral, as principais doenças do trabalho são: lesão por esforço repetitivo (LER), os distúrbios mentais provocados pelo estresse, as lombalgias, as perdas auditivas, os problemas oculares.

As "novas" gestões da força de trabalho, a desregulamentação e a precarização das relações sob a reestruturação produtiva e o neoliberalismo, estão limitando os trabalhadores pelo medo do desemprego. A competitividade é acirrada por um posto de trabalho, o que interfere na constituição da "consciência de classe" e no reconhecimento que constrói as subjetividades que se nutrem pela lógica do trabalho. Diante desse quadro, a intensificação do trabalho, a polivalência e a submissão impõem-se de forma ululante, o que origina uma situação propícia a mudanças do perfil patológico dos trabalhadores. Ao mesmo tempo em que é anunciado o "fim do trabalho", observa-se o surgimento de patologias decorrentes da cada vez maior sobrecarga: burnout ${ }^{4}$, as LER, as alterações cognitivas, as tentativas de suicídio nos locais de trabalho, os indicadores de estresse no trabalho (LACAZ, 2002, p. 11).

Os principais fatores geradores de acidentes e doenças ocupacionais estão relacionados aos salários e aos benefícios inadequados; maquinários e instalações impróprios, principalmente em setores da produção que se utilizam dos recursos da terceirização, quarteirização; descumprimento da legislação de saúde e segurança do trabalho; programas de prevenção e controle de riscos desconectado da realidade das empresas; cultura do Equipamento de Proteção Individual (EPI) e de mudanças de comportamento humano. A lógica conservadora que paira em relação ao EPI, julga que os acidentes resultam, sobretudo, de comportamentos "inadequados" dos acidentados, isto é, da prática de atos inseguros pelos trabalhadores, em especial pelo não uso do EPI. Essa concepção advoga que o EPI proporciona uma vida sem acidentes no trabalho. Mas, ao tratar o EPI como panaceia, desconsidera os outros fatores que envolvem a saúde do trabalhador.

Segundo dados oferecidos por Freitas (2010), em 2008 foram registrados cerca de 750 mil acidentes de trabalho no Brasil. Comparado com 2007, o número de acidentes de trabalho aumentou 13,4\%. O maior impacto deste aumento $(69,5 \%)$ deveu-se aos acidentes sem Comunicação de Acidente de Trabalho (CAT) registrada, oriunda da nova sistemática de concessão dos benefícios acidentários. Os subgrupos da Classificação Brasileira de Ocupações (CBO) com maior número de acidentes típicos foram os trabalhadores de funções transversais (recursos humanos, marketing, comunicação, auditoria, controle de gestão, contabilidade, compras, serviços gerais), totalizando $14,1 \%$. Os acidentes de trajeto são mais frequentes com os trabalhadores dos serviços, $18,6 \%$. Em relação às doenças do trabalho, os escriturários respondem por $13,7 \%$. De acordo com o Código Internacional de Doenças (CID), as 50 ocorrências de maior incidência nos acidentes de trabalho foram ferimento do punho e da mão, dorsalgia e fratura ao nível do punho ou da mão. Nas doenças do trabalho, as mais incidentes foram sinovite e tenossinovite, lesões no ombro e dorsalgia. Nos acidentes típicos e nos de trajetos, a faixa etária decenal com maior incidência foi a constituída por pessoas de 20 a 29 anos com, respectivamente, $39,8 \%$ e $41,5 \%$ do total de acidentes registrados. Nas doenças de trabalho, a faixa de maior incidência foi a de 30 a 39 anos, com $31,9 \%$ do total de acidentes registrados. Benefícios devido a acidentes e doenças do trabalho mais o pagamento das aposentadorias especiais decorrentes das condições ambientais do trabalho somaram 11,60 bilhões de reais/ano. Despesas como o custo operacional do Instituto Nacional do Seguro Social (INSS) mais as despesas na área da saúde e afins atingem, anualmente, 46,40 bilhões de reais.

Diante da abordagem feita e dos dados obtidos, percebemos que a relação saúde e trabalho expressa as várias causas e os vários fatores que desencadeiam os acidentes e as doenças, tanto no âmbito da produção, como também nos espaços externos que envolvem a vida do trabalhador.

\section{Considerações finais}

A saúde do trabalhador sofre todos os castigos impostos à força de trabalho. É nesse contexto, incômodo ao trabalho, que as organizações de luta em defesa dos direitos da classe trabalhadora devem estar atentas à saúde e aos processos causadores das doenças e dos acidentes de trabalho, pois as "leis tendências" da lógica do capital, quando tomadas de forma natural e eterna, não possibilitam a crítica e a reivindicação em defesa da saúde do trabalhador. Mas quando há possibilidades de entender as "leis tendências como relações históricas e transitórias"5, encontramos caminhos que podem protagonizar novas conquistas para a classe trabalhadora.

Parafraseando Lacaz (2002, p.17-18), as lutas no âmbito da saúde do trabalhador, principalmente nas políticas públicas e na prática sindical, devem criar estratégias que ampliem o controle social sobre os serviços e as ações de saúde. E, incorporar na atividade dos serviços, em toda a sua rede, ações de assistência e vigilância que partam do conhecimento do território e das necessidades da população, considerando as áreas de risco e o parque produtivo, para que a intervenção sobre os fatos geradores de agra- 
vos à saúde, oriundos dos processos de trabalho, tenham a eficácia e a abrangência necessárias. Tratase também, de elevar a consciência sanitária tanto da população que mora e trabalha na área de ação das Unidades de Saúde, como dos próprios servidores públicos, numa aliança que permita elevar a cidadania a patamares que deem autonomia aos projetos populares de participação e maior grau de interferência sobre as decisões relativas às políticas públicas. Para tal, é mister pensar na possibilidade de transformar propostas tímidas e conservadoras como o Programa de Agentes Comunitários de Saúde (PACS) e o Programa de Saúde da Família (PSF) em espaços criativos e aglutinadores das demandas de saúde, procurando, por exemplo, diante da cada vez maior incidência do trabalho domiciliar, articular o momento da (re)produção social (consumo mais produção), com o momento da produção (locais de trabalho). Tal meta poderia ser alcançada através da realização de censos de morbidade e cadastramentos populacionais que permitam uma maior aderência da população aos Serviços de Saúde locais, na perspectiva de implantação do Distrito Sanitário, construído como um processo social que dê conta dos problemas individuais e coletivos de saúde. Essa estratégia deve ocorrer baseada na efetiva participação dos trabalhadores e no envolvimento dos setores organizados da comunidade tais como os sindicatos, as associações de moradores, as comunidades de base, as organizações não governamentais. É através da participação e da organização que se poderá superar os obstáculos que se antepõem à conquista da saúde e à melhoria das condições de trabalho, transformando-o em algo prazeroso e potencializador das capacidades humanas.

As reivindicações em defesa da saúde do trabalhador devem ser encaradas como principal agenda das lutas dos trabalhadores, dos profissionais e dos gestores das políticas sociais voltadas para a saúde. Atender à demanda saúde do trabalhador é uma condição emergencial no processo de construção de uma sociedade, para que, no futuro, os trabalhadores tenham saúde para o trabalho e para a vida. Uma vida repleta de sentido que transcenda as amarras da exploração do trabalho como condição do desenvolvimento social.

Um fator que ganha destaque em relação à saúde do trabalhador, diz respeito aos cursos de formação de profissionais (em Direito, Medicina, Enfermagem, Serviço Social, Engenharia) que irão atuar nas políticas de atenção à saúde do trabalhador. Nesses cursos, deve ser privilegiada uma formação intelectual que reconheça a tensa relação entre capital e trabalho, para evitar intervenções que possam julgar culpado e punir o trabalhador em sua condição de acidentado ou adoecido.

Outra questão de suma importância, ao analisar a saúde do trabalhador, é colocar o movimento sindical como protagonista, e, no contexto atual, exigir um sindicalismo que vá além do sindicalismo tradicional. Pensamos o sindicalismo como um dos principais espaços de luta social em defesa de uma sociedade emancipada sendo, portanto, necessário perquirir impenitentemente um projeto social potencializador da lógica do trabalho. Sem esse pressuposto não visualizamos a menor relevância em analisar a saúde do trabalhador. Quando enunciamos lutas sociais do trabalho, remetemo-nos diretamente à desejada conquista da emancipação do trabalho e, simultaneamente, convocamos a perspectiva revolucionária que objetiva "transcender" a sociedade de classes sociais antagônicas.

Diante dos desafios colocados em relação à saúde do trabalhador, advertimos ser necessário pensar as possíveis configurações de organização política da classe trabalhadora. Emerge como tarefa do dia fortalecer o sindicalismo. Aquele sindicalismo que proporcione formação e clareza política aos trabalhadores. Um sindicalismo de corte classista, com seus dirigentes e trabalhadores conscientes, que ofereça condição política para promover uma classe operária instruída e não submetida à degradação material e espiritual (ALVES, 2006).

Devemos buscar, ininterruptamente, o espaço para fortalecer o debate que objetive a organização de uma classe trabalhadora capaz e articulada em suas tarefas de construção de uma nova sociedade em que a saúde do trabalhador seja plena em todas as suas dimensões.

\section{Referências}

ALVES, G. Trabalho e sindicalismo no Brasil dos anos 2000: dilemas da era neoliberal. In: ANTUNES, R. Riqueza e miséria do trabalho no Brasil. São Paulo: Boitempo, 2006. p. 461-474.

ANTUNES, R. Adeus ao trabalho? Ensaio sobre as metamorfoses e a centralidade do mundo do trabalho. São Paulo: Cortez, 2000.

Os sentidos do trabalho: ensaio sobre a afirmação e a negação do trabalho. São Paulo: Boitempo, 2001.

FREITAS, M. Política e saúde do trabalhador no contexto sindical. Seminário de Saúde do Trabalhador de Franca, IV e Seminário, V - O Trabalho em Debate. Mini-Curso. Fundacentro, 2010.

LACAZ, F. A. C. Saúde do trabalhador: cenários e perspectivas numa conjuntura privatista. Informe União Internacional dos Trabalhadores na Alimentação, Montevideo-Uruguai, 2002. (digitado). 
MARX, K.; ENGELS, F. A ideologia alemã. Tradução de José Carlos Brunni e Marco Aurélio Nogueira. São Paulo: Hucitec, 1999.

MARX, K. O capital: crítica da economia política. São Paulo: Abril Cultural, 1984. Livro primeiro, tomo 2.

Capítulo VI, Inédito de O capital: resultados do processo de produção imediata. São Paulo: Moraes, 1985.

O capital: crítica da economia política. Tradução de Reginaldo Sant'Anna. Rio de Janeiro: Civilização Brasileira, 2002a. Livro I, v. 1e v. 2.

MASLACH, C.; SCHAUFELI, W. B.; LEITER, M. P. Job Burnout. Annual Review of Psychology, n. 52, p. 397-422, 2001.

MÉSZÁROS, I. A teoria da alienação em Marx. Tradução de Isa Tavares. São Paulo: Boitempo, 2006.

MINAYO-GOMEZ, C.; THEDIM-COSTA, S. M. F. O campo da saúde do trabalhador - percursos e dilemas. Cadernos de Saúde Publica, v. III, n. 3, p. 21-32, 1997.

SANTOS, M. A. A reestruturação produtiva e seus impactos na saúde do trabalhador. Serviço Social \& Sociedade, São Paulo, ano 26, n. 82, p. 73-85, jul. 2005.

TRISTÃO, E. L. Práxis humana e subsunção do trabalho ao capital. In: SEMINÁRIO DO TRABALHO, VI. Trabalho, economia e educação no século XXI. Anais... Marília, Unesp, 2008

\section{Notas}

1 “A produção da mais-valia absoluta se realiza com o prolongamento da jornada de trabalho além do ponto em que o trabalhador produz apenas um equivalente ao valor de sua força de trabalho e com a apropriação pelo capital desse trabalho excedente. Ela constitui o fundamento do sistema capitalista e o ponto de partida da produção da mais-valia relativa. Esta pressupõe que a jornada de trabalho já esteja em duas partes: trabalho necessário e trabalho excedente. Para prolongar o trabalho excedente, encurta-se o trabalho necessário com métodos que permitem produzir-se em menos tempo o equivalente ao salário. A produção da mais-valia absoluta guia exclusivamente em torno da duração da jornada de trabalho; a produção da mais-valia relativa revoluciona totalmente os processos técnicos de trabalho e as combinações sociais"(MARX, 2002,p. 578).

2 Mészáros (2006) formula os conceitos de "mediação de primeira ordem" - atividade produtiva como tal, fator ontológico da condição humana e "mediação de segunda ordem" - ou "mediação da mediação" alienada, decorrente da propriedade privada, da troca, da divisão do trabalho. Segundo Mészáros (2006,p. 78), "O que Marx combate como alienação não é a mediação em geral, mas uma série de mediações de segunda ordem (propriedade privada intercâmbio - divisão do trabalho), uma 'mediação da mediação', istoé, uma mediação 'historicamente específica' de automediação 'ontologicamente fundamental' do homem com a natureza. Essa 'mediação de segunda ordem' só pode nascer com base na ontologicamente necessária 'mediação de primeira ordem' - como a 'forma específica', 'alienada', desta última. Mas a própria 'mediação de primeira ordem' - a atividade produtiva como tal-é um fator ontológico absoluto da condição humana."

3 Observe a afirmação de Marx (2002,p. 199): “A naturezanão produz, de um lado, possuidores de dinheiro ou de mercadorias e, de outro, meros possuidores das próprias forças de trabalho. Esta relação não tem sua origem na natureza, nemé mesmo uma relação social que fosse comum a todos os períodos históricos. Ela é, evidentemente, o resultado de um desenvolvimento histórico anterior, o produto de muitas revoluções econômicas, do desaparecimento de toda uma série de antigas formações da produção social."

4 Burnouté uma síndrome psicológica resultante de estresses interpessoais crônicos no trabalho (MASLACH; SCHAUFELI; LEITER, 2001).

5 O mundo não é algo dado imediatamente por toda a eternidade, uma coisa sempre igual a si mesma, mas o produto do estágio social, ou seja, a sociedade é "um produto histórico, o resultado da atividade de toda uma série de gerações, cada uma das quais se alcança aos ombros da precedente, desenvolvendo sua indústria e seu comércio, modificando a ordem social de acordo com as necessidades alteradas" (MARX;ENGELS, 1999,p.67).

\section{Ricardo Lara}

ricbrotas@ig.com.br

Doutor em Serviço Social pela Universidade Estadual Paulista Júlio de Mesquita Filho (Unesp)

Professor do Departamento de Serviço Social e do Programa de Pós-Graduação em Serviço Social da Universidade Federal de Santa Catarina (UFSC)

\section{UFSC - Programa de Pós-Graduação em Servi- ço Social}

Campus Universitário Reitor João David Ferreira Lima

Bairro Trindade

Florianópolis - Santa Catarina

CEP: 88040-970 